\title{
Manejo da pastagem de azevém, contaminação larval no pasto e infecção parasitária em ovinos
}

\author{
Eliezer José Pegoraro(1), César Henrique Espírito Candal Poli(1), Paulo César de Faccio Carvalho(2), \\ Mary Jane Tweedie de Mattos Gomes ${ }^{(3)}$ e Vivian Fischer ${ }^{(1)}$
}

(1)Universidade Federal de Rio Grande do Sul (UFRGS), Faculdade de Agronomia, Departamento de Zootecnia, Caixa Postal 15.100, CEP 91501-970 Porto Alegre, RS. E-mail: eliezerpegoraro@yahoo.com.br, cesar.poli@ufrgs.br, vfried@portoweb.com.br (2)UFRGS, Departamento de Plantas Forrageiras e Agrometeorologia. E-mail: paulocfc@ufrgs.br ${ }^{(3)}$ UFRGS, Faculdade de Veterinária, Departamento de Patologia Clinica Veterinária, Avenida Bento Gonçalves, no 9.090, CEP 91540-000 Porto Alegre, RS. E-mail: mary.gomes@ufrgs.br

Resumo - O objetivo deste trabalho foi avaliar o efeito do manejo da pastagem de azevém sobre o risco de reinfecção parasitária. Foram utilizadas duas ofertas ( 10 e $20 \mathrm{~kg}$ de matéria seca por $100 \mathrm{~kg}$ de peso vivo) em dois métodos de pastejo (lotação contínua e intermitente). A infestação parasitária no mantilho e nos diferentes estratos da forragem foi avaliada nos estratos: acima de $15,10-15,5-10,2,5-5$ e $0-2,5 \mathrm{~cm}$; a carga parasitária no animal foi avaliada por exames coproparasitológicos; e a seletividade da dieta foi avaliada com afilhos marcados. Independentemente do método, a densidade larval aumentou do topo para a base do dossel forrageiro. No entanto, entre os estratos aptos ao pastejo foram observadas diferenças na oferta de $20 \%$ do peso vivo. A oferta influenciou o número de larvas recuperadas na forragem e a infecção no animal para ambos os gêneros de parasitas Haemonchus spp. e Trichostrongylus spp. A maior oferta proporcionou maior contaminação larval e infecção nos ovinos, porém na oferta de $10 \%$ do peso vivo, a quantidade de larvas presentes no pasto foi menor em lotação contínua, mas a carga parasitária no animal foi semelhante à da lotação rotacionada, independentemente do método de pastejo.

Index terms: Haemonchus, Trichostrongylus, cordeiro, epidemiologia, método de pastejo, oferta de forragem.

\section{Italian ryegrass management, pasture larval contamination and parasitic infection in sheep}

\begin{abstract}
The objective of this work was to evaluate the effect of Italian ryegrass management pasture on parasite reinfection risk. The pasture was submitted to two forage offers (10 and $20 \mathrm{~kg}$ of dry matter by $100 \mathrm{~kg}$ live weight) in two grazing methods (set stocking and rotational). The parasitic infestation was analyzed in litter and in different forage strata: above $15,10-15,5-10,2.5-5$, and $0-2.5 \mathrm{~cm}$; parasitic burden in sheep was evaluated through parasitological tests; and marked tillers were used for selective diet evaluation. Independently of the method, larval density increased from the top to the base of sward canopy. However, among grazing strata, differences were observed when forage allowance was $20 \%$ of live weight. The offer influenced the number of larvae recovered in the pasture and the animal infection for both parasite genera Haemonchus spp. and Trichostrongylus spp. The highest offer provided the highest recovery of infective larvae and animal infection. However, at low forage offer (10\% live weight), infective larva in pasture was lower in set stocking, but the animal parasitic burden was similar to the rotational stocking, independently of the grazing method.
\end{abstract}

Index terms: Haemonchus, Trichostrongylus, lamb, epidemiology, grazing method, forage offer.

\section{Introdução}

Os nematódeos parasitas do trato gastrintestinal estão entre os principais entraves da produção ovina no Brasil. É necessário fazer o controle dos nematódeos para que a criação não se torne economicamente inviável, devido à baixa produtividade, à alta mortalidade dos animais e às despesas com mão-de-obra e anti-parasitários (Amarante, 2001). Esse cenário se agrava ainda mais na ovinocultura moderna, seja pela criação em áreas reduzidas, com pastoreio em lotação contínua ou pela utilização de altas taxas de lotação. Com a exploração intensiva das áreas de pastagem e a superlotação dos piquetes, ocorre um pastejo menos seletivo, diminuindo as áreas de rejeição ao redor das fezes, o que, em tese, levaria à maior ingestão de larvas infectantes (Gordon, 2000).

Do total da carga parasitária ovina, estima-se que mais de 95\% encontra-se nas pastagens (Bowman 
et al., 2003). Há muitas controvérsias a respeito de como o manejo da pastagem influencia a carga parasitária em ovinos. Ofertas mais elevadas podem levar a um microclima favorável à sobrevivência e ao desenvolvimento dos estágios larvais. No entanto, essas podem evitar que o animal ingira as larvas infectantes, pois, ao ingerir o estrato superior, as chances de contaminação são reduzidas. Conforme Carvalho et al. (1999), o estrato pastejado pelos ovinos corresponde, preferencialmente, a aproximadamente $50 \%$ da porção superior da planta estendida. Levando-se em consideração essas características do comportamento ingestivo dos ovinos, tem-se recomendado manter alturas residuais relativamente elevadas, a fim de evitar que os ovinos tenham acesso às larvas infectantes concentradas, em sua grande maioria, nos estratos inferiores.

Por sua vez, o maior rebaixamento da forragem, pode ser benéfico ao expor as larvas à radiação solar e à ação dos ventos. No entanto, em estruturas mais reduzidas, em alguns casos, além de os ovinos não obterem uma dieta de boa qualidade ou em quantidades suficientes, o risco de ingerir larvas infectantes aumenta, caso as condições climáticas favoreçam os estágios larvais.

O objetivo deste trabalho foi avaliar o efeito do manejo de azevém sobre o risco de reinfecção parasitária.

\section{Material e Métodos}

O trabalho foi conduzido no período invernoprimaveril, de agosto a novembro de 2006, na Estação Experimental Agronômica da Universidade Federal do Rio Grande do Sul, em Eldorado do Sul, localizada na Depressão Central do Rio Grande do Sul (30 ${ }^{\circ} 5^{\prime 2} 2$ "S; $\left.51^{\circ} 39^{\prime} 8^{\prime \prime} \mathrm{W}\right)$. A temperatura média ao longo do período experimental foi de $16,5^{\circ} \mathrm{C}$ e a umidade relativa do ar de $80,4 \%$.

A área experimental faz parte de um programa de integração lavoura-pecuária, onde a cultura de verão explorada é milho ou soja. A baixa contaminação inicial da pastagem foi verificada pela primeira coleta de forragem, realizada antes da entrada dos animais na área experimental.

Os tratamentos foram compostos por duas ofertas de forragem, que representam 2,5 ou 5 vezes o potencial de consumo dos animais. Como o potencial de consumo de ovinos em matéria seca, segundo o National Research Council (2007), é de 4\% do seu peso vivo, a oferta de forragem utilizada foi de 10 e de $20 \%$ de peso vivo, em dois métodos de pastejo: lotação contínua (LC) (pastoreio continuo) e lotação intermitente (LI) (pastoreio rotacionado), denominados então: LC 10\%; LI $10 \%$; LC $20 \%$; LI $20 \%$. Por meio desse manejo obtiveram-se estruturas de pastagem diferenciadas pela altura e massa da forragem (Tabela 1).

Para o experimento foram utilizadas quatro repetições por tratamento, num total de 16 piquetes. Em ambos os métodos, para o manejo da carga animal pretendida, em cada tratamento de oferta, foram utilizados número variável de animais reguladores pela técnica "put-and-take" (Mott \& Lucas, 1952). Os períodos de ajustes de oferta levaram em consideração o tempo de vida da folha (TVF), estabelecendo assim a duração de cada ciclo de pastejo e, por conseqüência, os respectivos períodos de descanso na lotação intermitente. Para tal, dados obtidos por Pontes et al. (2003) em experimentos anteriores foram considerados. Desta forma, para otimizar o aproveitamento das lâminas foliares e evitar a senescência delas, cada ciclo teve duração de 32,26 , 24, 20 dias para primeiro, segundo, terceiro e quarto ciclos de pastejo, respectivamente.

Foram utilizadas 101 borregas de três raças: Texel (41), Ile de France (33) e Suffolk (27), com idade aproximada de nove meses. Deste total, 48 foram considerados como animais avaliadores, e permaneceram todo o período experimental em sua respectiva unidade experimental, sendo utilizados três animais para cada unidade experimental (um de cada raça). Esses animais apresentavam carga parasitária

Tabela 1. Altura do dossel forrageiro $(\mathrm{cm})$, massa de forragem $(\mathrm{kg})$, escores de condição corporal $(\mathrm{CC}$, de 0 a 5$)$ e ganho médio diário de peso (GMD, $\mathrm{kg}$ por dia), ao longo do período experimental.

\begin{tabular}{|c|c|c|c|c|c|c|c|c|}
\hline \multirow[t]{3}{*}{ Método de pastejo } & \multicolumn{8}{|c|}{ Oferta de forragem } \\
\hline & \multicolumn{4}{|c|}{$10 \%$ do peso vivo } & \multicolumn{4}{|c|}{$20 \%$ do peso vivo } \\
\hline & Altura & Massa & $\mathrm{CC}$ & GMD & Altura & Massa & $\mathrm{CC}$ & GMD \\
\hline Lotação contínua & 13,40 & $1.897,50$ & 2,5 & 0,137 & 21,38 & $2.610,42$ & 2,4 & 0,152 \\
\hline Lotação intermitente & 20,70 & $2.476,25$ & 2,5 & 0,099 & 26,57 & $3.145,00$ & 2,4 & 0,125 \\
\hline
\end{tabular}


leve de aproximadamente 150 ovos por grama de fezes. Ao longo do experimento, os animais mantiveram uma condição corporal média e obtiveram ganhos médios diários de peso moderados (Tabela 1).

Para avaliação da infestação da pastagem, foram coletadas três amostras por piquete, em pontos aleatoriamente determinados. Essas coletas foram realizadas mensalmente de julho a outubro no total de quatro datas de cortes, ao longo do período experimental, sendo que para composição das médias de cada repetição não foram considerados os valores da primeira coleta realizada antes da entrada dos animais.

Para avaliar a presença de larvas nas diferentes alturas da forragem, o corte do pasto foi estratificado em cinco camadas. $O$ corte começou no estrato superior (acima de $15 \mathrm{~cm}$ ), e em seguida foram realizados os cortes sucessivamente nos extratos de $10-15 \mathrm{~cm}$, $5-10 \mathrm{~cm}, 2,5-5 \mathrm{~cm}, 0-2,5 \mathrm{~cm}$ e por último foi coletada uma amostra do mantilho (material senescente sobre o solo). Para evitar a interferência do fototropismo na migração larval, cada bloco (repetição) foi coletado em diferentes horários do dia, às $8,10,14$ e $16 \mathrm{~h}$. As amostras de cada estrato foram obtidas por meio de um estratificador, composto de uma estrutura retangular com dimensões de 30x41 cm e uma régua graduada pela qual o retângulo desliza-se até as alturas desejadas.

As amostras foram acondicionadas em sacos de plástico previamente identificados, mantidas refrigeradas em caixa térmica e posteriormente em refrigerador à temperatura média de $10^{\circ} \mathrm{C}$, por período máximo de 48 horas, e em seguida encaminhadas ao Laboratório de Helmintologia e Veterinária da Faculdade de Veterinária da UFRGS.

No laboratório retirou-se uma subamostra de $10 \mathrm{~g}$ de matéria verde para contagem do número de larvas presentes nos diferentes estratos, com base no termoidrotropismo, conforme técnica de Baermann modificada, descrita por Castro et al. (2003). As amostras de capim foram mergulhadas nos funis com água destilada esterilizada, aquecida a $50^{\circ} \mathrm{C}$, por 24 horas. Em seguida, o sobrenadante foi desprezado e uma alíquota de $10 \mathrm{~mL}$ foi retirada e transferida para um tubo para leitura em microscópio óptico, com aumento de 40 vezes.

A infecção parasitária no animal foi determinada pela contagem de ovos por grama de fezes (OPG), a cada ciclo de pastejo, utilizando-se a técnica de Gordon
\& Withlock (1939) modificada. Posteriormente, foi realizada a cultura de fezes pelo Método de Roberts e O'Sullivan (Ueno \& Gonçalves, 1998) para identificação dos gêneros presentes nas fezes.

Para avaliar o estrato da pastagem preferencialmente pastejado pelos animais, adotou-se a técnica de afilhos marcados (Carrère et al., 1997). Em cada unidade experimental da lotação contínua, foram marcados 60 afilhos nas unidades de oferta de $20 \%$ de peso vivo e 40 afilhos na oferta de $10 \%$. Na lotação intermitente foram marcados 20 afilhos por unidade experimental. A identificação de cada afilho foi realizada com auxílio de fio de telefone colorido, distribuído ao longo de transectos, marcando-se dez afilhos por transecto, distanciados aproximadamente $50 \mathrm{~cm}$ entre si. A alocação dos transectos foi realizada de forma a representar toda a área do piquete, evitando-se as proximidades da cerca. Na lotação intermitente, os afilhos marcados foram observados antes e após o pastejo na respectiva faixa de pastejo, e na lotação contínua em intervalos de 3-4 dias. O processo de marcação das unidades vegetativas foi refeito a cada ciclo de pastejo.

$\mathrm{Na}$ avaliação de cada afilho marcado, mediu-se a altura da lígula de cada folha e da maior distância entre cada lâmina foliar e o solo. Por diferença, pela constatação de pastejo, ou não, foram determinados os afilhos consumidos. Inicialmente foram marcados somente afilhos intactos (folhas não pastejadas), no entanto, ao longo do experimento foi necessário marcar afilhos já pastejados, sendo realizada marcação na ponta da folha a fim de que novos eventos de desfolhação fossem detectados. Como foi necessário estabelecer uma relação com a infestação parasitária, as alturas foram descritas neste trabalho dentro de cada estrato, conforme os cortes da forragem para a avaliação de larvas infectantes.

Os dados de recuperação de larvas na forragem foram analisados utilizando-se o delineamento de blocos ao acaso, em arranjo fatorial $2 \times 2 \times 6$ (dois métodos, duas ofertas e seis estratos). Os dados de contagem de ovos por grama de fezes foram analisados utilizando-se o arranjo fatorial $2 \times 2$ (dois método, duas ofertas), sendo a unidade experimental o piquete. Os dados foram transformados pelo método dos mínimos quadrados ponderados e em seguida analisados pelo procedimento GLM do SAS (SAS Institute, 2000), e as médias foram comparadas pelo teste Tukey, a 5\% de probabilidade. 


\section{Resultados e Discussão}

Houve interação significativa entre método de pastejo e oferta de forragem $(\mathrm{p}<0,05)$ para contagem de larvas. As pastagens mantidas em maior oferta propiciaram maior recuperação de larvas infectantes ao longo do período experimental (Tabela 2). Comparando isoladamente os métodos de utilização da pastagem (lotações contínua e intermitente), não houve diferença no número de larvas recuperadas. Uma das explicações para as diferenças encontradas seria a estrutura da pastagem. Na lotação contínua e oferta de $10 \%$ do peso vivo houve a manutenção da forragem em alturas que possivelmente favoreceram maior dessecação das larvas infectantes. Na lotação intermitente ocorreu o rebaixamento instantâneo da forragem, porém com período curto de exposição ou restabelecimento da estrutura ao longo do período de descanso, não permitindo a redução do nível de infestação da pastagem. Barger (1999) relata que a utilização da lotação intermitente como ferramenta para diminuir a carga parasitaria é mais usual em regiões de clima tropical do que em regiões de clima temperado. Neste trabalho, a lotação intermitente, por si, não foi eficiente no controle da infestação da pastagem. Conforme Souza et al. (2000), para ocorrer uma redução apreciável no número de larvas na pastagem é necessário de 98 a 112 dias no período de inverno e de 42 a 58 dias na primavera. Certamente o período de rotação deveria ser bem maior para que os animais não se contaminassem novamente.

Ao avaliar a distribuição das larvas nos diferentes estratos da pastagem, verificou-se maior recuperação

Tabela 2. Número de larvas $\mathrm{L}_{3}$ de Haemonchus spp. e de Trichostrongylus spp., recuperadas em amostras de $10 \mathrm{~g}$ de matéria verde da pastagem de azevém, em dois métodos de pastejo e duas ofertas de forragem ${ }^{(1)}$.

\begin{tabular}{lccc}
\hline Método de pastejo & \multicolumn{3}{c}{ Oferta de forragem } \\
\cline { 2 - 4 } & $\begin{array}{l}10 \% \text { do peso } \\
\text { vivo }\end{array}$ & $\begin{array}{c}20 \% \text { do peso } \\
\text { vivo }\end{array}$ & Média \\
\hline Larvas $\mathrm{L}_{3}$ de Haemonchus spp. \\
Lotação contínua & $0,8016 \mathrm{Aa}$ & $4,6597 \mathrm{Bb}$ & $2,8593 \mathrm{~A}$ \\
Lotação intermitente & $2,5000 \mathrm{Bb}$ & $3,5139 \mathrm{Bb}$ & $3,0069 \mathrm{~A}$ \\
\hline Média & $1,7074 \mathrm{a}$ & $4,0868 \mathrm{~b}$ & - \\
\hline \multicolumn{4}{c}{ Larvas $\mathrm{L}_{3}$ de Trichostrongylus spp. } \\
Lotação contínua & $1,5079 \mathrm{Aa}$ & $10,2847 \mathrm{Bb}$ & $6,1889 \mathrm{~A}$ \\
Lotação intermitente & $8,0972 \mathrm{Bb}$ & $9,4306 \mathrm{Bb}$ & $3,0069 \mathrm{~A}$ \\
\hline Médias & $5,0222 \mathrm{a}$ & $9,8576 \mathrm{~b}$ & - \\
\hline (1) Médias seguidas de letras iguais, maiúsculas nas colunas e minúsculas nas \\
linhas, não diferem entre si pelo teste de Tukey, a 5\% de probabilidade.
\end{tabular}

de larvas nos estratos inferiores da forragem (Tabela 3). A maior concentração de larvas infectantes na parte inferior da planta foi relatada por Vlassof (1982). Esse autor observou que $80 \%$ das larvas infectantes localizavam-se nos primeiros $5 \mathrm{~cm}$ do relvado em pastagem de azevém. Posteriormente, Moss \& Vlassoff (1993), ao avaliar a distribuição de larvas de nematódeos gastrintestinais em diferentes estratos das plantas, observaram que $28,1 \%$ das $\mathrm{L}_{3}$ encontravam-se na base da planta, $38,1 \%$ entre 2,6-7,5 cm de altura, $14,95 \%$ entre 7,6-12,5 $\mathrm{cm} \mathrm{e}$ $18,85 \%$ acima de $12,5 \mathrm{~cm}$. Porém, a localização das larvas infectantes nos diferentes estratos pode ser influenciada pelo manejo da pastagem, em especial a oferta de forragem, pela transformação do microclima proporcionada pela cobertura vegetal. Neste trabalho houve interação significativa entre oferta de forragem e estrato para contagem de larvas. Em oferta de $20 \%$ do peso vivo, foram observadas diferenças $(\mathrm{p}<0,05)$ dos estratos da base do dossel forrageiro e do material senescente junto ao solo (mantilho), comparados aos estratos superiores (Tabela 3), para os dois gêneros estudados (Haemonchus spp. e Trichostrongylus spp.). Em relação à oferta de $10 \%$ do peso vivo, não foram observadas diferenças $(p>0,05)$ entre os estratos aptos ao pastejo (exceto mantilho), para os dois gêneros estudados (Haemonchus spp. e Trichostrongylus spp.). A baixa concentração de larvas infectantes na forragem,

Tabela 3. Número de larvas $\mathrm{L}_{3}$ de Haemonchus spp. e de Trichostrongylus spp., por estrato, recuperadas em amostras de $10 \mathrm{~g}$ de matéria verde da pastagem de azevém, em duas ofertas de forragem ${ }^{(1)}$.

\begin{tabular}{lcc}
\hline Estrato & \multicolumn{2}{c}{ Oferta de forragem } \\
\cline { 2 - 3 } & $10 \%$ do peso vivo & $20 \%$ do peso vivo \\
\hline & Larvas de $\mathrm{L}_{3}$ de & Haemonchus spp. \\
Mantilho & $3,27 \mathrm{Aa}$ & $9,89 \mathrm{Aa}$ \\
$0-2,5 \mathrm{~cm}$ & $2,29 \mathrm{ABa}$ & $7,29 \mathrm{Aa}$ \\
$2,5-5 \mathrm{~cm}$ & $2,37 \mathrm{ABab}$ & $4,14 \mathrm{ABab}$ \\
$5-10 \mathrm{~cm}$ & $1,08 \mathrm{ABb}$ & $2,16 \mathrm{ABab}$ \\
$10-15 \mathrm{~cm}$ & $0,66 \mathrm{Bb}$ & $0,95 \mathrm{Bab}$ \\
Acima de $15 \mathrm{~cm}$ & $0,00 \mathrm{Bb}$ & $0,06 \mathrm{Bb}$ \\
\hline & Larvas de $\mathrm{L}_{3}$ de & Trichostrongylus $\mathrm{spp}$. \\
Mantilho & $6,87 \mathrm{Ab}$ & $25,06 \mathrm{Aa}$ \\
$0-2,5 \mathrm{~cm}$ & $7,52 \mathrm{Ab}$ & $14,79 \mathrm{ABb}$ \\
$2,5-5 \mathrm{~cm}$ & $8,68 \mathrm{Ab}$ & $8,95 \mathrm{BCbc}$ \\
$5-10 \mathrm{~cm}$ & $3,62 \mathrm{Ab}$ & $5,58 \mathrm{BCbc}$ \\
$10-15 \mathrm{~cm}$ & $1,75 \mathrm{Abc}$ & $4,14 \mathrm{BCbc}$ \\
Acima de $15 \mathrm{~cm}$ & $0,00 \mathrm{Abc}$ & $0,60 \mathrm{Cbc}$ \\
\hline
\end{tabular}

${ }^{(1)}$ Médias seguidas de letras iguais, maiúsculas nas colunas e minúsculas nas linhas, não diferem entre si pelo teste de Tukey, a 5\% de probabilidade. 
em ofertas de $10 \%$ na lotação contínua possivelmente fez com que essa diferença entre os estratos não fosse significativa.

Entre os dois gêneros observados na pastagem, constatou-se maior prevalência de Trichostrongylus spp., porém, nos animais houve maior presença do gênero Haemonchus spp. (Tabela 4). Essas diferenças observadas devem-se às condições climáticas durante o experimento (Figura 1) e ao potencial biótico. As condições climáticas prejudicaram o desenvolvimento do gênero Haemonchus, por ser mais sensível às temperaturas amenas e às umidades reduzidas. A temperatura ótima para a sobrevivência das larvas é de 18 a $26^{\circ} \mathrm{C}$ (Onyah \& Arslan, 2005).

O potencial biótico é definido como a capacidade de multiplicação em razão do tempo. No caso do Haemonchus spp., a capacidade é bastante elevada, com uma oviposição diária entre 5.000 e 10.000 ovos, muito superior ao do Trichostrongylus spp., de 100-200 ovos por dia (Romero \& Boero, 2001).

A verificação da carga parasitária dos animais demonstrou que a oferta de forragem determinou diferenças $(p<0,05)$ no grau de infecção (Tabela 5$)$. As maiores quantidades de larvas encontradas a $20 \%$ de oferta na pastagem resultaram em animais com maior carga parasitária. Fato também evidenciado por Gastaldi et al. (2001) e Amarante et al. (2004), que encontraram associação entre o número de larvas infectantes na

Tabela 4. Percentagem do total de larvas $\mathrm{L}_{3}$ de Haemonchus spp. e de Trichostrongylus spp. recuperadas na pastagem de azevém e da avaliação de coprocultura, em dois métodos de pastejo e duas ofertas de forragem.

\begin{tabular}{|c|c|c|}
\hline \multirow[t]{2}{*}{ Método de pastejo } & \multicolumn{2}{|c|}{ Oferta de forragem } \\
\hline & $10 \%$ do peso vivo & $20 \%$ do peso vivo \\
\hline & \multicolumn{2}{|c|}{$\begin{array}{c}\text { Larvas } \mathrm{L}_{3} \text { de Haemonchus spp. na } \\
\text { pastagem }\end{array}$} \\
\hline Lotação contínua & 35,02 & 29,18 \\
\hline \multirow[t]{2}{*}{ Lotação intermitente } & 23,57 & 28,29 \\
\hline & \multicolumn{2}{|c|}{$\begin{array}{c}\text { Larvas } \mathrm{L}_{3} \text { de Trichostrongylus spp. na } \\
\text { pastagem }\end{array}$} \\
\hline Lotação contínua & 64,98 & 70,82 \\
\hline \multirow[t]{2}{*}{ Lotação intermitente } & 76,43 & 71,71 \\
\hline & \multicolumn{2}{|c|}{$\begin{array}{l}\text { Larvas } \mathrm{L}_{3} \text { de Haemonchus spp. na } \\
\text { coprocultura }\end{array}$} \\
\hline Lotação contínua & 95,00 & 95,00 \\
\hline \multirow[t]{2}{*}{ Lotação intermitente } & 93,33 & 95,00 \\
\hline & \multicolumn{2}{|c|}{$\begin{array}{c}\text { Larvas } \mathrm{L}_{3} \text { de Trichostrongylus spp. na } \\
\text { coprocultura }\end{array}$} \\
\hline Lotação contínua & 5,00 & 5,00 \\
\hline Lotação intermitente & 6,66 & 5,00 \\
\hline
\end{tabular}

pastagem (Haemonchus spp. e Trichostrongylus spp.) e a contagem de ovos por grama de fezes dos ovinos.

$\mathrm{Na}$ avaliação da seletividade ou estrato preferencial de pastejo, foram observadas diferenças $(p<0,05)$ entre os tratamentos (Tabela 6). Preferencialmente, os ovinos buscaram folhas mais jovens, que normalmente são encontradas nos estratos superiores da planta. Carvalho et al. (1999) destaca que o estrato preferencialmente pastejado pelos ovinos corresponde a aproximadamente $50 \%$ da porção superior da planta estendida.

Nos tratamentos de maior oferta $(20 \%$ do peso vivo), a localização preferencial de pastejo deu-se nos estratos superiores de 10-15 cm, e acima de $15 \mathrm{~cm}$. Quando a oferta diminui pela metade $(10 \%$ do peso vivo), o animal é forçado também a selecionar sua dieta no estrato intermediário da pastagem. Para o método rotativo, os animais pastejam, além dos estratos superiores, o estrato de $5-10 \mathrm{~cm}$. No método de pastejo contínuo, na oferta de $10 \%$ do peso vivo, os animais encontram uma baixa opção de seleção nos estratos superiores, em decorrência da altura média das lâminas foliares, que força os animais a pastejarem, além do estrato intermediário $(5-10 \mathrm{~cm})$, os estratos inferiores $(2,5-5 \mathrm{~cm})$.

Os riscos de ingestão de larvas infectantes e infecção parasitária foram menores nas ofertas de $20 \%$ do peso vivo (Tabela 6), pois os animais selecionaram basicamente a sua dieta nos estratos superiores, relativamente com menores concentrações de larvas infectantes. No entanto, as avaliações de contagem de

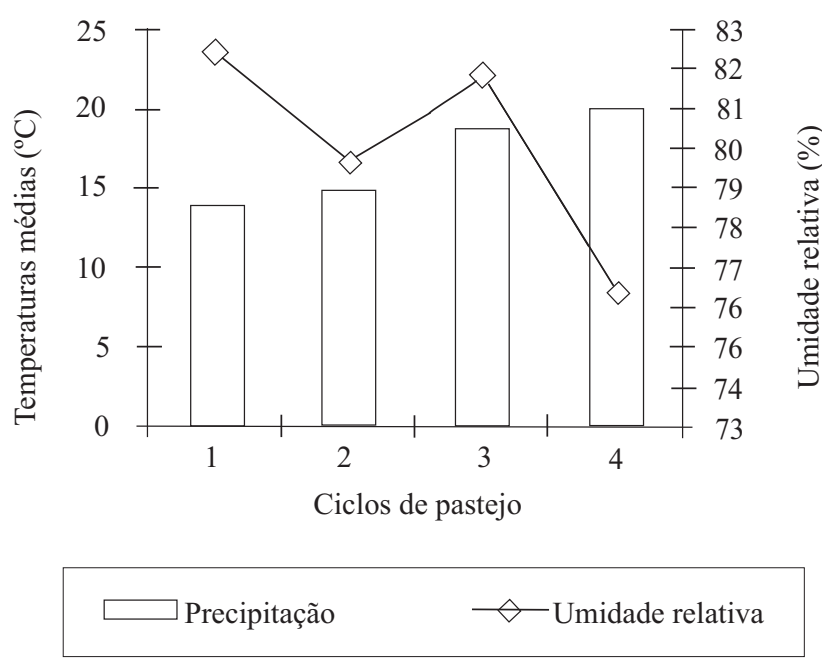

Figura 1. Valores médios de temperatura $\left({ }^{\circ} \mathrm{C}\right)$ e umidade relativa do ar (\%) ao longo dos quatro ciclos de pastejo. 
Tabela 5. Número de ovos por grama de fezes (OPG) coletados em ovinos, em dois métodos de pastejo e duas ofertas de forragem ${ }^{(1)}$.

\begin{tabular}{lcc}
\hline Método de pastejo & \multicolumn{2}{c}{ Oferta de forragem } \\
\cline { 2 - 3 } & $10 \%$ do peso vivo & $20 \%$ do peso vivo \\
\hline Lotação contínua & $1.032,64 \mathrm{~b}$ & $3.237,19 \mathrm{a}$ \\
Lotação intermitente & $413,44 \mathrm{~b}$ & $3.023,94 \mathrm{a}$ \\
\hline
\end{tabular}

${ }^{(1)}$ Médias seguidas de letras iguais na mesma coluna não diferem entre si pelo teste de Tukey, a 5\% de probabilidade.

Tabela 6. Valores percentuais para o extrato preferencial de pastejo nos métodos de utilização da pastagem em lotação contínua (LC) e em lotação intermitente (LI) e nas ofertas de forragem de 10 e $20 \%$ do peso vivo.

\begin{tabular}{lrrrr}
\hline Estrato & \multicolumn{4}{c}{ Método de pastejo/oferta de forragem } \\
\cline { 2 - 5 } & LC $10 \%$ & LI $10 \%$ & LC $20 \%$ & LI $20 \%$ \\
\hline $0-2,5 \mathrm{~cm}$ & 0,00 & 0,00 & 0,00 & 0,00 \\
$2,5-5 \mathrm{~cm}$ & 20,74 & 5,23 & 0,25 & 0,00 \\
$5-10 \mathrm{~cm}$ & 43,30 & 30,59 & 14,42 & 13,15 \\
$10-15 \mathrm{~cm}$ & 21,48 & 35,38 & 28,27 & 21,85 \\
Acima de $15 \mathrm{~cm}$ & 14,48 & 28,80 & 57,06 & 65,00 \\
\hline
\end{tabular}

ovos por grama de fezes (Tabela 5) indicaram que os animais que estavam na oferta de $20 \%$ do peso vivo apresentaram a maior carga parasitária. Provavelmente, a quantidade de larvas infectantes recuperadas, a essa oferta, predispõe o animal a ingerir quantidade superior de $\mathrm{L}_{3}$ e, por conseqüência, apresentar maiores quantidades de ovos por grama de fezes. Maior ingestão de forragem em estrato inferior na lotação contínua, em oferta de $10 \%$ do peso vivo, pode ser responsável por maior ingestão de larvas infectantes. Esse fato levou a cargas parasitárias semelhantes, mesmo que o número de larvas recuperadas na forragem para essa oferta tenha sido inferior aos apresentados na lotação intermitente. A manutenção das lâminas foliares em baixas alturas residuais diminuiu o nível de infestação da pastagem. No entanto, a seleção da dieta foi prejudicada levando o animal a consumir os estratos inferiores e, conseqüentemente, a apresentar maior risco de reinfecção.

\section{Conclusões}

1. Independentemente do método de pastejo utilizado ou da oferta de forragem, a densidade larval em pastos de azevém aumenta do topo para a base do dossel forrageiro.

2. A oferta de forragem equivalente a $20 \%$ do peso vivo propicia maior quantidade de larvas no pasto e ainda que as concentrações sejam menores nos estratos pastejados pelos ovinos, essa é suficiente para estabelecer maior carga parasitaria no animal.

3. Na oferta de $10 \%$ do peso vivo, a quantidade de larvas presentes no pasto é menor em lotação contínua, mas a carga parasitaria no animal é semelhante à da lotação intermitente, pois nesta, a participação do estrato inferior na dieta do animal é maior.

\section{Referências}

AMARANTE, A.F.T. do. Controle de endoparasitoses ovinas. In: REUNIÃO DA SOCIEDADE BRASILEIRA DE ZOOOTECNIA, 38., 2001, Piracicaba. A produção animal na visão dos brasileiros. Piracicaba: Fealq, 2001. p.461-473.

AMARANTE, A.F.T. do; BRICARELLO, P.A.; ROCHA, R.A.; GENNARI, S.M. Resistance of Santa Ines, Suffolk and Ile de France sheep to naturally acquired gastrointestinal nematode infections. Veterinary Parasitology, v.120, p.91-106, 2004.

BARGER, I.A. Control of gastrointestinal nematodes in Australia in the $21^{\text {st }}$ century. Veterinary Parasitology, v.46, p.23-32, 1993.

BOWMAN, D.D.; LYNN, R.C.; EBEHARD, M.L. Georgi's parasitology for veterinarians. $8^{\text {th }}$ ed. St. Louis: Saunders, 2003. 422p.

CARRÈRE, P.; LOUAULT, F.; SOUSSANA, J.F. Tissue turnover within grass-clover mixed swards grazed by sheep. Methodology for calculating growth, senescence and intake fluxes. Journal of Applied Ecology, v.34, p.333-348, 1997.

CARVALHO, P.C.F.; PRACHE, S.; ROGUET, C.; LOUAULT, F. Defoliation process by ewes of reproductive compared to vegetative swards. In: INTERNATIONAL SYMPOSIUM ON THE NUTRITION OF HERBIVORES, 4., 1999, San Antonio. Proceedings. San Antonio: [s.n.], 1999.

CASTRO, A.A. de; ALMEIDA, R.L. de; SILVA, F.J.M. da; GUEDES JUNIOR, D. da S.; OLIVEIRA, C.J. de; ORNELAS, E.I. de; FONSECA, A.H. da. Comparação entre as técnicas de Baermann modificada e Donald utilizadas para recuperar larvas infectantes de nematóides gastrintestinais de ruminantes da pastagem. Revista Brasileira de Parasitologia Veterinária, v.12, p.88-91, 2003.

GASTALDI, K.A.; SILVA SOBRINHO, A.G. da; COSTA, A.J. da; ROCHA, U.F. da. Variação estacional do número de ovos por grama de fezes de nematódeos parasitas de ovinos na região de Jaboticabal, São Paulo. ARS Veterinária, v.17, p.124-129, 2001.

GORDON, H.M.; WHITLOCK, H.V. A new technique for counting nematode eggs in sheep faeces. Journal of the Council for Scientific and Industrial Research, v.12, p.50-52, 1939.

GORDON, I.J. Plant-animals interactions in complex plant communities: from mechanism to modeling. In: LEMAIRE, G.; HODGSON, J.; MORAES, A. de; CARVALHO, P.C. de F.; NABINGER, C. (Ed.). Grassland ecophysiology and grazing ecology. Wellingford: CAB International, 2000. p.191-207. 
MOSS, R.A.; VLASSOFF, A. Effect of herbage species on gastro-intestinal roundworm populations and their distribution. New Zealand Journal of Agricultural Research, v.36, p.371-375, 1993.

MOTT, G.O.; LUCAS, H.L. The design conduct and interpretation of grazing trials on cultivated and improved pastures. In: INTERNATION GRASSLAND CONGRESS, 6., 1952. Proceedings. Pensylvania: State College Press, 1952. p.1380-1395.

NATIONAL RESEARCH COUNCIL. Nutrient requirements of small ruminants: sheep, goats, cervids, and new world camelids. Washington: National Academic Press, 2007. 362p.

ONYIAH, L.C.; ARSLAN, O. Simulating the development period of a parasite of sheep on pasture under varying temperature conditions. Journal of Thermal Biology, v.30, p.203-211, 2005.

PONTES, L. da S.; NABINGER, C.; CARVALHO, P.C. de F.; SOARES, A.B. Fluxo de biomassa em pastagem de azevém anual
(Lolium multiflorum Lam.) manejada em diferentes alturas. Revista Brasileira de Zootecnia, v.33, p.529-537, 2003.

ROMERO, J.R.; BOERO, C.A. Epidemiología de la gastroenterites verminosa de los ovinos em las regiones templadas y cálidas de la Argentina. Analecta Veterinaria, v.21, p.21-37, 2001.

SOUZA, P. de; BELLATO, V.; SARTOR, A.A.; RAMOS, C.I. Período para desinfestação das pastagens por larvas de nematóides gastrintestinais de ovinos, em condições naturais nos campos de Lages, SC. Revista Brasileira de Parasitologia Veterinária, v.9, p.159-164, 2000.

UENO, H.; GONÇALVES, P.C. Manual para diagnóstico das helmintoses de ruminantes. 4.ed. Tóquio: Jica, 1998. 143p.

VLASSOF, A. Biology and population dynamics of the free-living stages of gastrointestinal nematodes of sheep. In: ROSS, A.D. Control of internal parasites in sheep. New Zealand: Lincoln College, 1982. p.11-20.

Recebido em 10 de abril de 2008 e aprovado em 11 de setembro de 2008 